\title{
Fachbuchreihe BAUKONSTRUKTIONEN
}

\begin{tabular}{|c|c|c|c|}
\hline \multirow[t]{8}{*}{ Band 1: } & \multicolumn{2}{|c|}{ Bauphysik } & \multirow[t]{8}{*}{ 2. Auflage 2018} \\
\hline & $010 \mid 1$ & Grundlagen & \\
\hline & $010 \mid 2$ & Winterlicher Wärmeschutz & \\
\hline & $010 \mid 3$ & Tauwasserschutz & \\
\hline & $010 \mid 4$ & Sommerlicher Wärmeschutz & \\
\hline & $010 \mid 5$ & Schallschutz & \\
\hline & $010 \mid 6$ & Brandschutz & \\
\hline & $010 \mid 7$ & Tabellen & \\
\hline \multirow[t]{12}{*}{ Band 1/1: } & \multicolumn{2}{|c|}{ Bauphysik - Erweiterung 1} & \\
\hline & \multicolumn{3}{|c|}{$\begin{array}{l}\text { Energieeinsparung und Wärmeschutz, Energieausweis - Gesamtenergieeffizienz } \\
011 / 1 \quad \text { Grundlagen }\end{array}$} \\
\hline & $011 \mid 2$ & Heizwärmebedarf & \\
\hline & $011 \mid 3$ & Beleuchtungsenergiebedarf & \\
\hline & $011 \mid 4$ & Kühlbedarf & \\
\hline & $011 \mid 5$ & Heiztechnikenergiebedarf & \\
\hline & $011 \mid 6$ & Raumlufttechnikenergiebedarf & \\
\hline & $011 \mid 7$ & Befeuchtungsenergiebedarf & \\
\hline & $011 \mid 8$ & Kühltechnikenergiebedarf & \\
\hline & $011 \mid 9$ & Bilanzierung & \\
\hline & $011 \mid 10$ & Energieausweis und Energiekennzahlen & \\
\hline & $011 \mid 11$ & Tabellen & \\
\hline \multirow[t]{9}{*}{ Band 2: } & \multicolumn{2}{|c|}{ Tragwerke } & 2. Auflage 2018 \\
\hline & $020 \mid 1$ & Grundlagen & \\
\hline & $020 \mid 2$ & Einwirkungen & \\
\hline & $020 \mid 3$ & Sicherheit & \\
\hline & $020 \mid 4$ & Linientragwerke & \\
\hline & $020 \mid 5$ & Flächentragwerke & \\
\hline & $020 \mid 6$ & Raumtragwerke & \\
\hline & $020 \mid 7$ & Bauwerke & \\
\hline & $020 \mid 8$ & Tabellen & \\
\hline \multirow[t]{7}{*}{ Band 3: } & \multicolumn{2}{|c|}{ Gründungen } & 2. Auflage 2020 \\
\hline & $030 \mid 1$ & Baugrund & \\
\hline & $030 \mid 2$ & Erddruck & \\
\hline & $030 \mid 3$ & Flachgründungen & \\
\hline & $030 \mid 4$ & Tiefgründungen & \\
\hline & $030 \mid 5$ & Baugruben & \\
\hline & $030 \mid 6$ & Bauen im Grundwasser & \\
\hline \multirow[t]{7}{*}{ Band 4: } & \multicolumn{2}{|c|}{ Wände } & 2. Auflage 2019 \\
\hline & $040 \mid 1$ & Grundlagen & \\
\hline & $040 \mid 2$ & Gemauerte Wände & \\
\hline & $040 \mid 3$ & Homogene Wände & \\
\hline & $040 \mid 4$ & Holzwände & \\
\hline & $040 \mid 5$ & Pfeiler und Stützen & \\
\hline & $040 \mid 6$ & Trennwände & \\
\hline \multirow[t]{7}{*}{ Band 5: } & \multicolumn{2}{|c|}{ Decken } & 1. Auflage 2006 \\
\hline & 050.1 & Grundlagen & \\
\hline & 050.2 & Massivdecken & \\
\hline & 050.3 & Holzdecken & \\
\hline & 050.4 & Verbunddecken & \\
\hline & 050.5 & Balkone und Loggien & \\
\hline & 050.6 & Unterdecken & \\
\hline \multirow[t]{6}{*}{ Band 6: } & \multicolumn{2}{|l|}{ Keller } & 1. Auflage 2006 \\
\hline & 060.1 & Funktion und Anforderung & \\
\hline & 060.2 & Konstruktionselemente & \\
\hline & 060.3 & Feuchtigkeitsschutz & \\
\hline & 060.4 & Detailausbildungen & \\
\hline & 060.5 & Schutzräume & \\
\hline
\end{tabular}




\begin{tabular}{|c|c|c|c|}
\hline \multirow[t]{6}{*}{ Band 7: } & \multicolumn{2}{|c|}{ Dachstühle } & \multirow[t]{6}{*}{ 2. Auflage 2017} \\
\hline & $070 \mid 1$ & Dachformen und Holztechnologie & \\
\hline & $070 \mid 2$ & Beanspruchungen und Bemessung & \\
\hline & $070 \mid 3$ & Verbindungsmittel & \\
\hline & $070 \mid 4$ & Dachstuhlarten & \\
\hline & $070 \mid 5$ & Sonderformen & \\
\hline \multirow[t]{7}{*}{ Band 8: } & \multicolumn{2}{|c|}{ Steildach } & 1. Auflage 2015 \\
\hline & $080 \mid 1$ & Grundlagen & \\
\hline & $080 \mid 2$ & Dachdeckungen und Materialien & \\
\hline & $080 \mid 3$ & Ungedämmte Dachflächen & \\
\hline & $080 \mid 4$ & Gedämmte Dachflächen & \\
\hline & $080 \mid 5$ & Metalldeckungen & \\
\hline & $080 \mid 6$ & Dachentwässerung & \\
\hline
\end{tabular}

$\begin{array}{lll}\text { Band 9: } & \text { Flachdach } & \text { 1. Auflage } 2011 \\ 090.1 & \text { Grundlagen } \\ 090.2 & \text { Konstruktionsschichten und Materialien } \\ 090.3 & \text { Nicht belüftete Dächer } \\ 090.4 & \text { Zweischaliges Dach } \\ 090.5 & \text { Genutzte Dachflächen } \\ 090.6 & \text { Dachentwässerung }\end{array}$

$\begin{array}{lll}\text { Band 10: } & \text { Treppen/Stiegen } & \text { 1. Auflage } 2005 \\ & 100.1 & \text { Grundlagen } \\ 100.2 & \text { Entwurfskriterien } \\ 100.3 & \text { Barrierefreie Erschließungen } \\ 100.4 & \text { Konstruktionsformen } & \\ 100.5 & \text { Aufzüge } & \end{array}$

$\begin{array}{lll}\text { Band 11: } & \text { Fenster } & \text { 1. Auflage } 2005 \\ & 110.1 & \text { Grundlagen } \\ 110.2 & \text { Typenentwicklung } \\ 110.3 & \text { Funktionen und Anforderungen } \\ 110.4 & \text { Verglasungs- und Beschlagstechnik } \\ 110.5 & \text { Baukörperanschlüsse }\end{array}$

Band 12:

Türen und Tore

1. Auflage 2007

$120.1 \quad$ Grundlagen

120.2 Funktionen und Anforderungen

120.3 Materialien

120.4 Beschläge und Zusatzbauteile

120.5 Türkonstruktionen

120.6 Torkonstruktionen

Band 13: $\quad$ Fassaden

$130.1 \quad$ Grundlagen und Anforderungen

130.2 Putzfassaden

130.3 Wärmedämmverbundsysteme

130.4 Leichte Wandbekleidung

130.5 Massive Wandbekleidungen

130.6 Selbsttragende Fassaden

130.7 Glasfassaden

Band 14: Fußböden

$\begin{array}{ll}140 \mid 1 & \text { Grundlagen } \\ 140 \mid 2 & \text { Konstruktionen und Materialien } \\ 140 \mid 3 & \text { Bodenbeläge } \\ 140 \mid 4 & \text { Fußbodenaufbauten und Details } \\ 140 \mid 5 & \text { Sportböden }\end{array}$

1. Auflage 2014 
Band 15:

$150.1 \quad$ Grundlagen

150.2 Wärmeversorgungsanlagen

150.3 Abgasanlagen

150.4 Kälteversorgungsanlagen

150.5 Wärme- und Kälteverteilung

150.6 Planung von Heizungs- und Kühlungssystemen

$150.7 \quad$ Nachhaltigkeit

Band 16:

Lüftung und Sanitär

1. Auflage 2006

160.1 Grundlagen der Lüftungs- und Klimatechnik

160.2 Lüftungs- und Klimaanlagen

160.3 Wärmerückgewinnung

160.4 Planung von Lüftungs- und Klimaanlagen

160.5 Begriffsbestimmungen zur Sanitärtechnik

$160.6 \quad$ Wasserversorgung

160.7 Entwässerung

160.8 Planung von Sanitäranlagen

Band 17: Elektro- und Regeltechnik

1. Auflage 2007

$170.1 \quad$ Grundlagen der Elektrotechnik

170.2 Erdungs- und Blitzschutzanlagen

170.3 Stromversorgung

170.4 Schalter, Steckgeräte, Leuchten, Lampen

170.5 Messwertgeber und Stellgeräte

170.6 Mess-, Steuer- und Regelanlagen

170.7 Kommunikationsanlagen

170.8 Planung Elektro- und Regelanlagen

Sonderband: Garagen

Problematik Verkehr

3. Auflage 2018

Planungsprozess

Gesetzliche Rahmenbedingungen

Entwurfsgrundlagen Garage

Entwurf Bauwerk

Mechanische Parksysteme

Oberflächengestaltung

Technische Ausrüstung

Benützung und Betrieb

Ausführungsbeispiele

Entwurfsschablonen PKW

Sonderband: Ziegel im Hochbau

2. Auflage 2018

Ziegelarchitektur

Baustoffe, Produkte

Bauphysik

Gebäudephysik

Mauerwerk - ein Verbundwerkstoff

Mauerwerksbemessung

Ausführung, Verarbeitung, Details

Nachhaltigkeit

Ausführungsbeispiele

Sonderband: Holz im Hochbau 1. Auflage 2016

$1 \quad$ Holzarchitektur

$2 \quad$ Holztechnologie - Baustoffe und Produkte

Bauphysik

Gebäudephysik

Konstruktionen des Holzbaus

Bemessung von Holzbauten

Bauteile, Aufbauten und Details

Ausführung und Vorfertigung

Verarbeitung und Qualitätssicherung

10 Ausschreibung

$11 \quad$ Nachhaltigkeit 